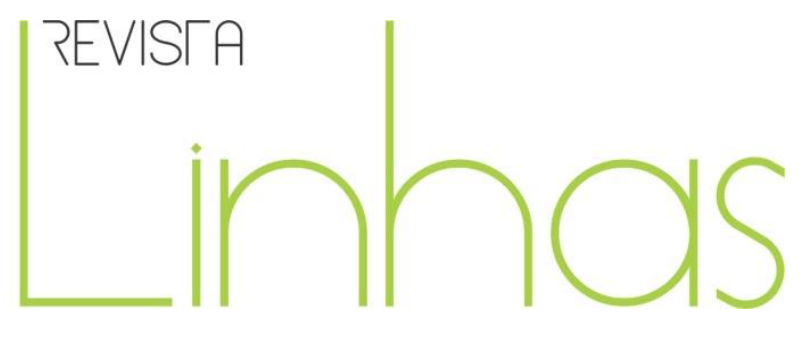

\title{
Resenha do livro "Educar en cine. Profesores en las películas de ficción desde el cine mudo hasta hoy"
}

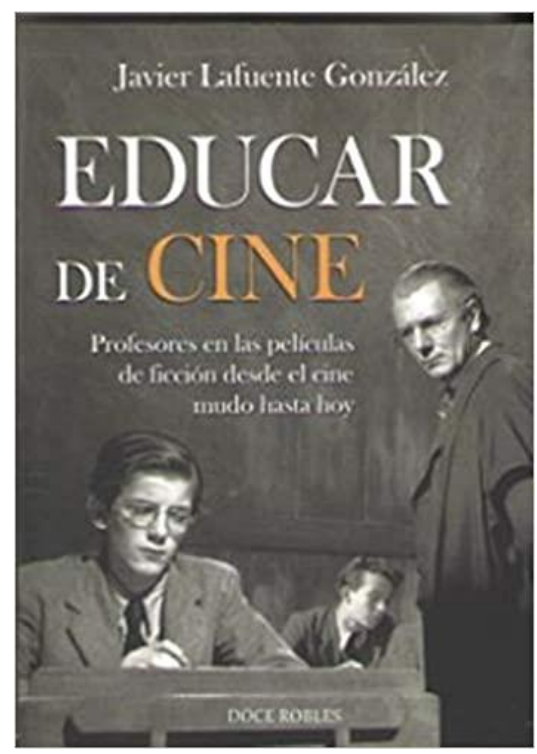

Javier Lafuente González: Educar en cine. Profesores en las películas de ficción desde el cine mudo hasta hoy. Doce Robles: Zaragoza, 2019, 476 p.

\section{Laura Pacheco-Jiménez}

Universidad de Sevilla - España

laurapachecojimenez@gmail.com

\section{Para citar esta resenha:}

PACHECO-JIMÉNEZ, Laura. Resenha do livro "Educar en cine. Profesores en las películas de ficción desde el cine mudo hasta hoy". Revista Linhas. Florianópolis, v. 21, n. 47, p. 405-410, set./dez. 2020. 
Todo alumno tiene o ha tenido algún profesor en su vida que le ha dejado huella. Bien por haberle motivado, por haberle ayudado a encontrar su vocación, o bien por todo lo contrario, pero existir, ha existido. Doce Robles, la editorial maña dedicada a temas históricos relacionados con Aragón, ha recogido en su último libro todo tipo de profesores representados en la historia del cine en un periodo que va desde el cine mudo hasta las cintas más recientes. Este libro casi enciclopédico lo firma Javier Lafuente González, periodista y escritor.

La introducción es apenas un bosquejo de lo que el lector va a encontrarse al sumergirse en el libro. Sin embargo, ya da un puñado de títulos que muestran lo habitual de la figura del profesor en el cine con películas como Amarcord (Federico Fellini, 1973), León, el profesional (Luc Besson, 1994) o La vida es bella (Roberto Benigni, 1997). En total se recogen 1.001 cintas que, con mayor o menor protagonismo, han incluido a un docente en su metraje. A pesar de su más que amplio corpus no hay que confundir esta obra con un libro de consulta o una de esos volúmenes de "mil y una..."; en primer lugar, porque no está estructurado como tal $\mathrm{y}$, en segundo, porque es un volumen para disfrutar en su totalidad, compuesto por análisis de mil y un profesores diferentes que bien merece la pena pararse a leer con detenimiento.

El primer capítulo lleva por nombre la mítica frase de Walter Whitman rescatada por El club de los poetas muertos (Peter Weir, 1989), “Oh, capitán, mi capitán”, y está dedicado a aquellos profesores que han dejado huella, los inolvidables, aquellos que son un ejemplo a seguir aunque no siempre consigan sus objetivos. Este apartado recoge cintas como Historias de la radio (José Luis Sáenz de Heredia, 1955), donde el maestro de un pequeño pueblo va a un concurso radiofónico para conseguir dinero y destinarlo a que un alumno vaya a Suecia a someterse a una operación que su familia no puede pagar. Otra cinta española es El cabezota (Francisco Lara Polop, 1982) que trata los inconvenientes a los que se enfrentan los profesores en algunas zonas rurales cuando se promulga la Ley Moyano, que estableció la educación primaria obligatoria en España. Además, el capítulo recoge filmes con docentes de multitud de países tales como La India con Aparajito (Satyajit Ray, 1957), la segunda entrega de la trilogía de Apu; México con Simitrio (1960), donde los estudiantes engañan a un profesor invidente haciéndole creer que quien hace las gamberradas es Simitrio, un alumno que está en las listas, pero que se ha ido del colegio. 
También se mencionan la estadounidense Los pájaros (Alfred Hitchcock, 1963), la francesa La piel dura (François Truffaut, 1976), la iraní A las cinco de la tarde (Samira Makhmalbaf, 2003) o la canadiense Profesor Lazhar (Philippe Falardeau, 2011). Especial mención merece la española Katmandú, un espejo en el cielo (Icíar Bollaín, 2011) cuyas protagonistas abren camino a la imagen de la profesora como heroína en un entorno de jóvenes sin recursos.

“Enseñar es un milagro” es el título del segundo bloque y está dedicado a la educación especial, aquí se dan cita películas que han representado escuelas para sordos o invidentes, especializadas en la psicoterapia del lenguaje y otras discapacidades como es el caso de Estrellas en la tierra (India, Aamir Khan, 2007), donde el protagonista padece una dislexia sin diagnosticar que ninguno de sus profesores comprende y lo derivan a otro centro, donde también es incomprendido hasta que se cruza con un profesor que también padeció la enfermedad en su juventud. Pero la dislexia no es la única enfermedad a la que se enfrentan los profesores de este grupo, otras son el síndrome de Tourette (Al frente de la clase, Peter Werner, 2008), el asperger (Adam, Max Mayer, 2009), o la discapacidad intelectual de una joven que sufre abusos sexuales por parte de su padre (Precious, Lee Daniels, 2009). Si bien las tres películas mencionadas son estadounidenses, también aquí hay diversidad territorial puesto que el polaco Andrzej Jakimowski dirigió Imagine (2012) sobre un profesor que llega a una clínica de oftalmología; o el coreano Hwang Dong-hyuk que llevó a la pantalla un caso real sobre violaciones en una escuela para niños sordomudos con el filme Silenced (2011), sucesos que destapa uno de los profesores. La importancia de estos docentes en la vida de sus alumnos con necesidades especiales es fundamental, es probablemente el bloque de películas donde la imagen de los profesores queda más ensalzada pues no son solo educadores, sino salvadores.

Cuando se trata la conflictividad en las aulas, tema que copa el tercer capítulo, normalmente son películas de un profesor con nuevas ideas e inquietudes que llega a un centro sin recursos y tiene que reinventar la metodología de la escuela haciendo frente a los contratiempos. Cintas como Rebelde sin causa (Nicholas Ray, 1955) o El barrio contra mí (Michael Curtiz, 1955) vienen inmediatamente a la cabeza, quizás incluso alguna más reciente como El profesor (Tony Kane, 2011). Sin embargo, Lafuente rescata, además de las mencionadas, una rareza: Violación en las aulas (Fernando Di Leo, 1969). La cinta italiana trata sobre la violación y posterior asesinato de una profesora y la ulterior investigación en 
la que se descubre que todos los alumnos han estado presentes. La moraleja final de que no hay que educar a las alimañas porque hay algunas que son casos perdidos, no puede dejar indiferente a nadie.

El cuarto capítulo hace un recorrido sobre profesores que tienen otras ocupaciones relacionadas con las aventuras o la guerra, por lo que es difícil verlos entre las cuatro paredes de un aula, sin embargo no dejan de ser docentes en sus nuevas experiencias. En este grupo destaca el personaje de la saga Indiana Jones, arqueólogo y aventurero, pero no es el único. El protagonista de la saga de El código Da Vinci (Ron Howard, 2006) es profesor de simbología, Los crímenes de Oxford (Álex de la Iglesia, 2013) está coprotagonizada por un profesor de lógica y Tesis sobre un homicidio (Hernán A. Goldfrid, 2013) por un abogado y profesor de Derecho Penal.

La segunda parte de este capítulo está centrada en la relación entre los docentes y las guerras y, de hecho, ésta está clasificada por conflictos bélicos diferenciados (Guerra de Secesión, Primera y Segunda Guerra Mundial, Guerra de Argelia, de Irak, etc.) para acabar con las clásicas películas del Oeste, empezando por la adaptación de la que es considerada la primera novela del Oeste The Virginian, llevada a la pantalla bajo el mismo título por Cecil B. DeMille en 1914, cuando el cine todavía era mudo.

Los capítulos quinto y sexto tratan las relaciones entre alumnos y docentes. El primero sobre enamoramiento y deseos sexuales entre profesores y estudiantes, y el segundo sobre esos maestros malvados, crueles o violentos que representan algunas películas y que marcan a sus pupilos para siempre. En 1931 nace en Alemania Muchachas de uniforme (Leontine Sagan y Carl Froelich) y se convirtió en la primera película en mostrar abiertamente una relación lésbica, esta cinta tuvo un remake mexicano homónimo en 1958 y otro estadounidense bajo el título Loving Annabelle (Katherine Brooks, 2006). El final trágico es algo que suele caracterizar a este grupo de películas, ya que las relaciones se esconden, son algo prohibido. Un paso más allá va la danesa La caza (Thomas Vinterberg, 2012) en la que la vida de un profesor se desmorona tras ser acusado de abusos sexuales a menores por error.

Entrando en esos docentes torturadores que dejan fluir su lado más oscuro, Lafuente destaca que tienden a representar la oposición para los profesores heroicos. Algunos de los ejemplos de este apartado son La prima Angélica (Carlos Saura, 1974), Los 
chicos del coro (Christophe Barratier, 2004) o la más reciente Whiplash (Damien Chazelle, 2014).

A continuación, hay tres capítulos clasificados según el género de los films en los que se encuentran a estos profesores, a saber: terror y ciencia ficción (séptimo capítulo), comedia (en el octavo) y drama (en el noveno y último).

Las adaptaciones de la novela de Bram Stoker Drácula han sido muchas, dos de las mencionadas son la de Laurence Olivier en 1979 o la de Francis Ford Coppola en 1992. Brian de Palma dirige Carrie en 1976 cuyo trasfondo es el de una joven alumna que sufre bullying en el colegio y, a la vez, tiene poderes telequinéticos. Una visión más cruel y apocalíptica muestra la distopía Battle Royale (Kinji Fukasaku, 2000) en la que una clase al azar se escoge cada año para obligar a sus alumnos a sobrevivir en una isla desierta. En ciencia ficción destaca la elección de Lafuente de incluir Monsters University (Dan Scanlon, 2013), la película de animación de Pixar que supone la precuela de Monstruos, S.A. (Pete Docter, Lee Unkrich y David Silverman, 2001) y que narra cómo se conocieron los protagonistas en la universidad para monstruos a la que asistieron.

En el octavo capítulo, el autor hace un repaso por la comedia desde los hermanos Marx hasta los profesores representados en las películas de Woody Allen como Balas sobre Broadway (1994). Llama la atención la elección de El profesor Aníbal una rareza húngara de Zoltán Fabri (1956) que está concebida como una comedia costumbrista pero que concluye con un final trágico, así como la africana Los dioses deben estar locos (Jamie Uys, 1980) en la que una tribu se ve inmersa en un conflicto bélico tras la aparición de una botella de CocaCola. No faltan en este grupo las grandes cintas de Berlanga como Bienvenido Mr. Marshal (1952) o Los jueves, milagro (1957).

En el grupo dedicado a las tragedias destacan las inclusiones de películas como Muerte de un ciclista (Juan Antonio Bardem, 1955) donde un profesor de universidad y su amante atropellan a un joven y se dan a la fuga para que no se descubra su relación, la clásica Los puentes de Madison (Clint Eastwood, 1995) o cintas más recientes como Concursante (Rodrigo Cortés, 2007) o La ola (Dennis Gansel, 2008) que supone una reflexión sobre el germen del nacismo en una escuela alemana. Lafuente firma un apartado especial dedicado a actuaciones de maestros ante el acoso escolar en films como Té y simpatía (Vicente Minelli, 1956) o Elephant (Gus Van Sant, 2003). 
Por ultimo se incluyen en el volumen algunos apartados extra como son: más

películas a tener en cuenta; las mejores películas, según los docentes -una pequeña encuesta de la que se muestran las votaciones, los votantes y los resultados-; un índice de las 1.0001 películas mencionadas a lo largo del libro y, por último, el apartado bibliográfico.

En definitiva, Educar de cine. Profesores en las películas de ficción desde el cine mudo hasta hoy es un ejemplar fascinante, una guía en la que va a ser difícil que al lector se le ocurra algún docente no recogido por Javier Lafuente González, un minucioso trabajo sobre una de las profesiones más importantes del mundo y con más relevancia para la sociedad: la del profesor. Cine y educación se dan la mano a lo largo de casi 500 páginas en las que le lector encontrará citas, películas por descubrir y un sinfín de docentes que, de forma consciente o no, han cambiado nuestra forma de ver la vida (y el cine).

\section{Referência}

Javier Lafuente González: Educar en cine. Profesores en las películas de ficción desde el cine mudo hasta hoy. Doce Robles: Zaragoza, 2019, 476 p.

Recebido em: 17/05/2020 Aprovado em: 20/06/2020

Universidade do Estado de Santa Catarina - UDESC Programa de Pós-Graduação em Educação - PPGE

Revista Linhas

Volume 21 - Número 47 - Ano 2020 revistalinhas@gmail.com 